\title{
IDETC2016-59826
}

\section{ANALYSIS ON EDUCATING MECHANICAL ENGINEERS THROUGH SERIOUS GAMES USING PERVASIVE TECHNOLOGIES}

\author{
Jannicke Madeleine Baalsrud Hauge \\ Bremer Institut für Produktion und Logistik an der \\ University of Bremen, Bremen, Germany \\ Royal Institute of Technology, Stockholm, Sweden
}

\author{
Theodore Lim \\ School of Engineering \& Physical Sciences \\ Heriot Watt University, Edinburgh, UK
}

\author{
Matthias Kalverkamp \\ University of Oldenburg, Oldenburg, \\ Germany
}

\author{
Florian Haase \\ Bremer Institut für Produktion \\ und Logistik an der University \\ of Bremen, Bremen, Germany
}

\author{
Francesco Bellotti \\ DITEN \\ University of Genoa, Genoa, Italy
}

\begin{abstract}
In the education of mechanical engineers alternative learning methods like serious games, simulations etc. have been used in past decades to better the learning outcomes. However, as digital technologies advance, so too does the quality of commercial game-based learning. This brings the expectation that while serious games are still considered as an experimental pedagogic vehicle, the learning experience among students and their experience of using serious games become heightened. This is a challenge for several educational games that though fully able to progress a learning goal, is deemed detached due to its dated user interface and inability to host the latest ICTs. This creates an unappealing aspect to the student and can also affect their motivation. This paper reports on the early efforts to analyze serious games from the perspective of learning and gaming mechanics and the virtual environment and systems that can be made pervasive. The intention is to re-furbish dated serious games that are highly relevant to educating mechanical engineers. The proposed concepts lie in the adoption of new pervasive technologies enabled by cyber-physical systems (CPS) and Internet of things (IoT) to modernize dated engineering serious games.
\end{abstract}

\section{INTRODUCTION}

Within business and engineering schools, the criticism of transferring knowledge lies in the conflicting benefits for relevant stakeholders effectively linking research results and actual (or future) practice has been well documented [1]. For students, several aspects related to production and product development in a collaborative environment are still mostly addressed primarily at a theoretical level. This makes it more difficult to understand the physical restrictions and opportunities in product design and development. In order to overcome the gap between theory and practice, engineering schools have been using experiential learning approaches, including simulation and game based learning in different settings. Game-based learning (GBL) [2-6] has been established as a significant tool, especially where normal class room settings have shown clear difficulties in content delivery $[8,9]$ fostering more direct interaction and participation of the students [9-12].

Educational content, through the use of simulations, when enhanced with gaming features can enable learners to cope with real problems and authentic situations that are close to reality [5, $13,14]$. In engineering-manufacturing, simulations play a part in the assimilating the science of mechanical design, e.g. computational fluid dynamics (CFD). However, the simulations in terms of graphic rendering do not need to mirror the real world perfectly. In engineering and management education, 
simulations are often scenario-based or case-based. Here, events of the real world are often used as a means to elicit critical decision-making. As such, simulations have attempted to mirror the real world. Typical examples of latter type of games are a game used for SCM, called Fresh Connection, simulating the whole supply chain or typical air traffic control and transport planning games. Even though the engineers to be educated are the same, the requirements the usage of the game are very different. Where as in the first case it is sufficient that the simulation is similar to the real world, it will often need to be exact the same in the latter case. Thus, this also requires that when new concepts like cyber physical systems are introduced, in which a user get real time data feedback in planning and operation of a system, this interaction needs to also be delivered in an educational game used to teach about the system. Thus, the main objective with this article is to describe the first approaches we have done on integration of censor data in educational games for production and logistics, based on previous experience in developing services for autonomous production systems and CPS in a living lab context.

\section{PROBLEM STATEMENT}

Though serious games (SG) have been used in engineering and management education their deployment rate remains low.[ There are two fundamental reasons. To a large extent because most of the games used are unique productions not commercially available but also because the gaming experience and the feedback given within the game play is not fulfilling the participants' expectations [5, 6]. User engagement is very dependent on the quality of facilitation, fitness of the SG to the subject, the content and context of use, combinatorial effects of learner types and user groups, interactivity and learning curve. Given that most SGs used in educating engineers are in house developed on a limited budget, the offered assets and support cannot be compared against commercial entertainment games. Furthermore, many games were developed at a time where immediate response and personalised feedback were not normative, and neither was the SGs designed with a clear focus on learning objectives.

However, these games can, and do, produce good learning outcomes [5]. Therefore, instead of developing new games with the same learning target, the intention here is to 'modernise' these SGs with new assets in the form of pervasive technologies that provide learners and facilitators a structured means to organise learning/tutoring, assessment, feedback and improved interactivity. As most of the games are developed for a workshop setting, we investigate how the games can better immersed/integrated the player-learner into the environment. This is to some extent the concept of Living labs and co-creative approaches used in product development. The application of entertainment games infrastructure with Wii and Kinect is known to engage and immerse players to quite high degree. Thus, a concept that allows physical objects to connect to virtual spaces anywhere at any time is likely to improve user experience. Such an infrastructure which connects virtual environments and systems can be achieved through pervasive technologies enabled by cyber-physical systems (CPS) and Internet of things (IoT).

CPS and IoT technologies allow connectable objects, sensors, actuators and even individuals' access to an interconnected network, bridging the physical-virtual world [1517]. Both use and/or incorporate existing technologies such as Radio-Frequency Identification technologies (RFID), service oriented architectures (SOA), interoperability platforms for data interchange, mobile technologies and global positioning systems.

This leads to a paradigm change in the way mechanical engineering will be taught. The main question is therefore how to design such an environment and which sensor data is relevant for mediating skills on mechanical engineering. This article intends to give a prospective analysis on how such a SG (virtual learning environment) can look like. The analysis is based on an existing game used for service development in production and logistics.

\section{BACKGROUND}

The prospective consideration on how to improve the user experience in games used for teaching mechanical engineers is based on both our experience in game based learning and our experience in co-creative design and participatory approaches for service development. Over the past decade, an open innovation environment (or real life environment), where different stakeholder groups can be involved, proved to offer a good environment for user involvement. Living Labs (LL) provide such environments and are today an established part of local and regional innovation systems [18]. LLs use a variety of methods and tools, focus on a wide array of domains and themes [19], as well as provide an open innovation environment to explore technologies under (almost) real conditions. Participants can co-create services; explore technologies and services; and experiment with them in conditions where failures do not cause an impact on operations. Services can be explored and tested even before hitting the market [18].

However, a LL is more than a testing lab for new products or services; it encourages the ideation process and especially looks at these new ideas from different perspectives. During the exploration phase, draft solutions are tested with mock-ups or prototypes. Results are then transferred into real environments for experimentation. After these steps, an evaluation of what has been developed throughout the iteration process takes place [20, $21,22]$. A successful ideation process is the foundation of every service development. Co-creative development does not always guarantee the successful development of new ideas and the resulting services may not meet the needs of the customer. Past experience has shown that the ideation phase is often considered to be the most challenging, and that there is a need of tools supporting the process. This process is very similar to many of the games used for educational purposes [23, 24, 25] supporting creativity and ideation at the University of Bremen for years. These games are running on an in-house build gaming engine, called engine be.mog [24]. Thus, within the ELLIOT the same engine was selected for developing the serious game scenario for 
IoT oriented user co-creation. The engine was selected, because of its purpose to elicit user needs. As the be.mog engine has been used before, some publications already exist and provide more details about the engine and on its application [24-26], and the emphasis was put on developing the interface between the gaming platform and the lab environment. The experience in this development process laid the foundation for the work looking into how to integrate real data into game environment, also for our educational games used for teaching different subjects to mechanical engineer students. Thus, the next section describes the observation for the LL development and how this was used for redesigning an educational game.

\section{INTEGRATING THE LIVING LAB AS A PART OF A GAME}

The theory of experiential learning is based upon the paradigm of constructivism. Kolb's four-stage learning cycle suggests how experience is translated through reflection into concepts, which in turn are used as guides for active experimentation and the choice of new experiences [26]. This four stage model fits quite well in combination with the four step process model of Living Labs, and the authors have good experiences with service development both within Living Labs and by using serious games in the ideation process [27].

Players are presented with information that they then have to interpret and interact with. Games can contain multiple and contradictory knowledge structures. According to Corti [28, p.1] Serious Games “is all about leveraging the power of computer games to captivate and engage end-users for a specific purpose, such as to develop new knowledge and skills”. Comparing the underlying processes and mechanisms for ideation and gaming shows that there are similarities. Based on this, an experiential learning environment for IoT service development and technology experiments was introduced.

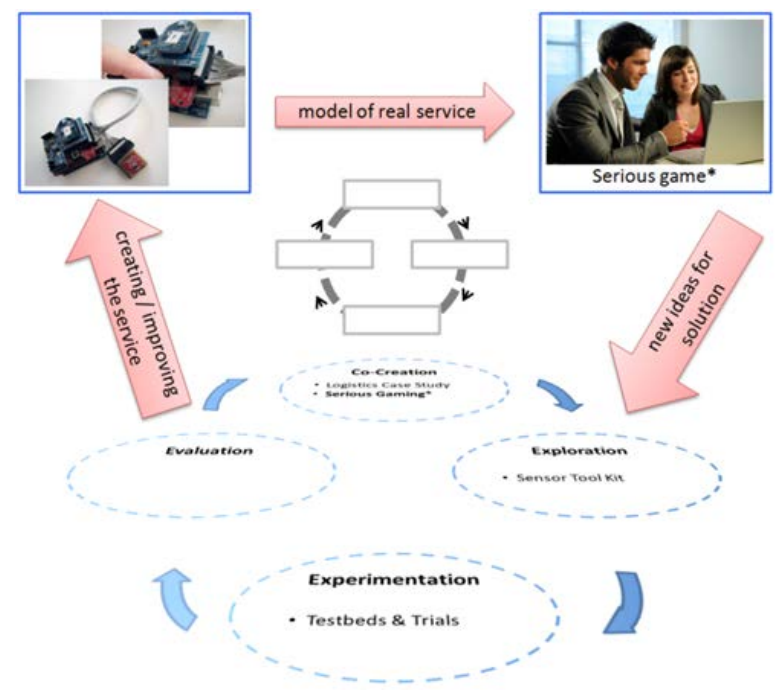

Figure 1: Connecting a Serious Game with a Living Lab
The idea of integrating the game directly in the lab environment was came out from the e need of integrating real and virtual world better, since this process have already started in the companies.

Figure 1 illustrates this approach. The learning cycle of Kolb (in the middle) illustrates that its learning styles are partly included in this approach. The individual purpose of a game determines which learning styles are used within the game. Based on the experience with this approach the toolkit (top left in the figure) which was formerly used only for exploration and experimentation (prototyping) should now be merged with the serious game (top right). This game has been prototypical implemented as described in [29]. Based on the experience with the Elliot game for IoT service development, we have analysed the underlying mechanics in order to identify possibilities to improve other games that we use for teaching mechanical engineers. This is described in the next section.

\section{THE UNDERLYING EXPERIMENTS}

The Elliot IoT game which was made for the purpose of supporting the development of new IoT based services in a Living Lab context was designed to be used for workshops with employees from the logistic sector. Thus, the platform had to fulfil the following requirements:

(1) a modular approach to attach new and detach old or unneeded sensors easily;

(2) an interface which allows observation and configuration by novices (non-experts, field experts; no coding required);

(3) ideally an Open Source approach, to provide potential for further adoption at low cost.

It is a an environment very similar to what our engineers meet when they leave university

Different IoT tool kits were examined, and Arduino was selected as the most suitable one for the purpose of the Elliot project. The data the participants generate is important in a game scenario designed for ideation. This game scenario is implemented using a game engine, be.mog. The toolkit as well as the game is briefly described here.

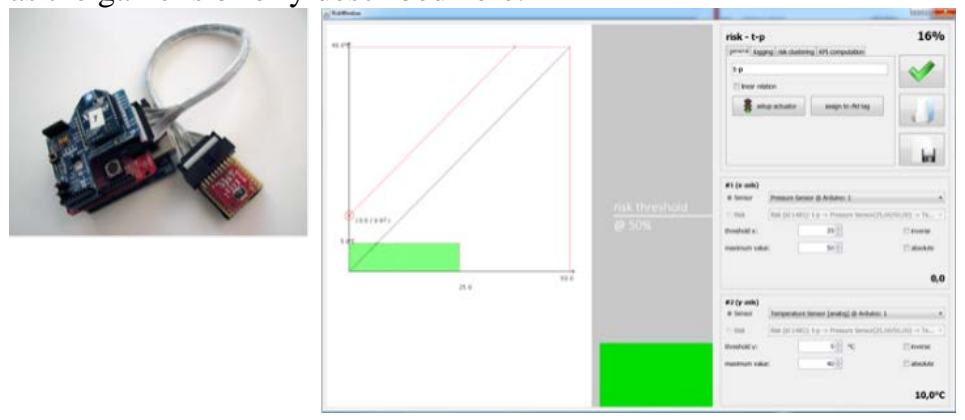

Figure 2: IoT Toolkit: Hardware (left) and GUI risk configuration (right)

The Arduino microcontroller family (Arduino One, LilyPad) was used in the IoT set up. The work reported in this article refers to the use of Arduino, as it was found to be the most appropriate solution at the time. 
Other open-source hardware solutions were not available at that time nor did they provide a GUI usable by novice users.

Modular IoT solutions are readily available; however, the configuration of sensor networks in terms of algorithms for sensed data and actuator response/action, still needs to be coded manually. Figure 2 shows the toolkit and its graphical user interface (GUI). The GUI provides a visual programming interface to configure the algorithms for the IoT services. The usage requires only little knowledge of programming, so that everybody can participate and develop their own service. In this first experiment, the main objective of the students participating in the lab was to develop different services. In order to test and develop the gaming application to be used for the IoT service development we used a participatory design approach in order to better understand how the students (our potential customer as course visitors) interacted with the technology in the hybrid environment. This is in our living lab context the co-creative phase.

The participants were aged from 20 to 29 years [21]. The operational tasks for the students (in the LL) was to rearrange the sensor selection of specific IoT services for fitting the usage in specific contexts.Table 1 shows some of the results for this experiment. The most frequently used sensors are RFID and accelerometer followed by temperature and humidity (one module). While initial setups did not focus on them, the distance sensor and the speed meter are listed due to their heavy use during exploration and testing during experimentation. The accelerometer was mainly used to observe the fork's angle or the whole forklift angle (risk of toppling of goods/forklift).

\begin{tabular}{|c|c|c|c|}
\hline Sensors & $\begin{array}{c}\text { Service } \\
1\end{array}$ & $\begin{array}{c}\text { Service } \\
2\end{array}$ & $\begin{array}{c}\text { Service } \\
3\end{array}$ \\
\hline Heartbeat & $\mathrm{x}$ & & \\
\hline Accelerometer & $\mathrm{x}$ & $\mathrm{x}$ & $\mathrm{x}$ \\
\hline RFID-Reader & $\mathrm{x}$ & $\mathrm{x}$ & $\mathrm{x}$ \\
\hline Humidity \& Temperature & & $\mathrm{x}$ & $\mathrm{x}$ \\
\hline GPS & & & $\mathrm{x}$ \\
\hline Gyroscope (3-Achsen) & & $\mathrm{x}$ & \\
\hline Air pressure/height & & & $\mathrm{x}$ \\
\hline Vibration & & $\mathrm{x}$ & $\mathrm{x}$ \\
\hline Pressure & & $\mathrm{x}$ & \\
\hline Temperature analogue & $\mathrm{x}$ & & \\
\hline Distance Ultra Sonic & \multirow{2}{*}{\multicolumn{3}{|c|}{$\begin{array}{l}\text { Used and tested during } \\
\text { exploration and experimentation }\end{array}$}} \\
\hline $\begin{array}{l}\text { Speed Meter / Driving } \\
\text { Direction Detector }\end{array}$ & & & \\
\hline
\end{tabular}

Table 1: Toolkit sensors used in exploration setup

RFID was applied to identify the transported goods, often with a cross-check of the environmental conditions such as temperature and humidity. Due to these configurations, the temperature and humidity sensor were then applied to observe sensible goods; in combination with the RFID such services would adapt accordingly to new situations, i.e. in case other products have different thresholds for temperature. From the observation of how the students interacted with the tool kit and the sensors during the co-creative phase. We analysed their engagement and as well as how fast they understood the relation between data and service as well as their willingness to explore new sensors. Whereas the engagement was high, the students were much more reluctant to experiment with different sensors in the co-creative phase and testing of the same sensors in the explorative phase. Based on feedback and analysis, the reason for this was the complexity of the system. The more experienced the participant were, the more experimentation they carried out.

As described above, the Elliot game is one of the scenarios running at the be.mog engine, even though not for educational purposes. This engine is also executing a game used for decision making in distributed environment. The game is based on real processes and existing cases, but since it is couple of years old there is no real interaction with real world data. The same holds for the information flow. This is all based on the underlying simulation processes and the feedback to the user via the screen. Thus the player is not immersed at all. However a part of the learning goals is connected to CPS and information flow. A revealing challenge have in the past years it has been a challenge to convey how different data can be used since the interaction with the game is the same, and nothing with what the student overserve in the environment. Thus, we looked at how the educational games running at the same engine could draw advantages of this and if it would improve the imersiveness and contribute to a better transparency of how different processes are influenced by different variables coming from the production process. The next section describe the game that we are currently redesigning in order to give the students a more immersive learning environment.

\section{THE REDESIGN OF AN EDUCATIONAL GAME IN A HYBRID ENVIRONMENT}

At the University of Bremen, the GBL courses have been offered to the students for the last two decades.

Beware is a web-based multi-player online game implemented in a workshop setting with three groups are in separate locations. The game objective is to handle risks occurring while developing and producing products/services in a distributed working environment with a minimum of $98 \%$ quality rate, in shortest possible time, and to the lowest possible cost, i.e. comprising both elements of concurrent engineering and supply chain management. The game is facilitated, and the facilitator can monitor the game play via the monitoring interface $[26,30]$. 


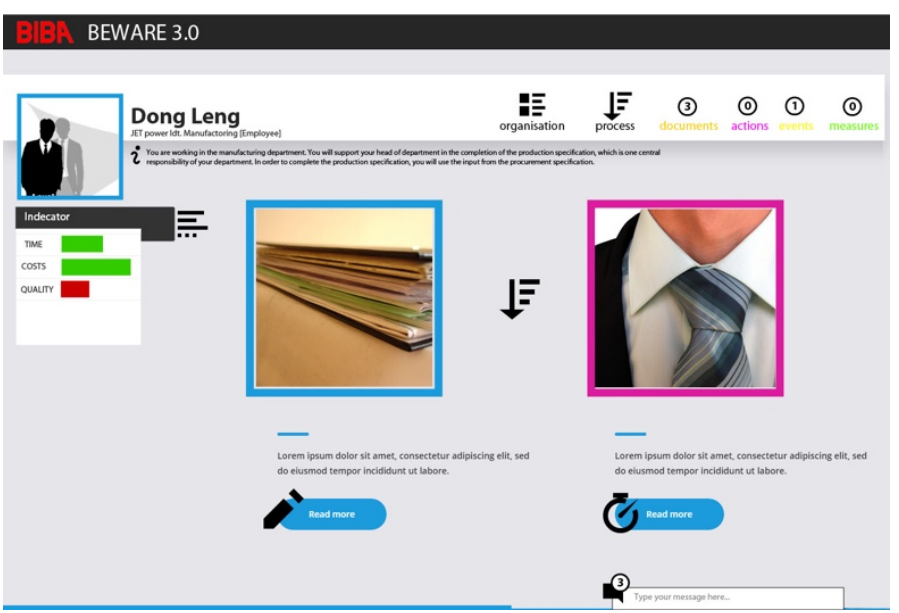

Figure 3: Design of new, customizable interface in Beware

The learning objectives of the Beware game in the setting described here are to increase the understanding and awareness of risks in supply networks and to improve the players' skills in supply chain risk management, as well as to apply common risk management methods.

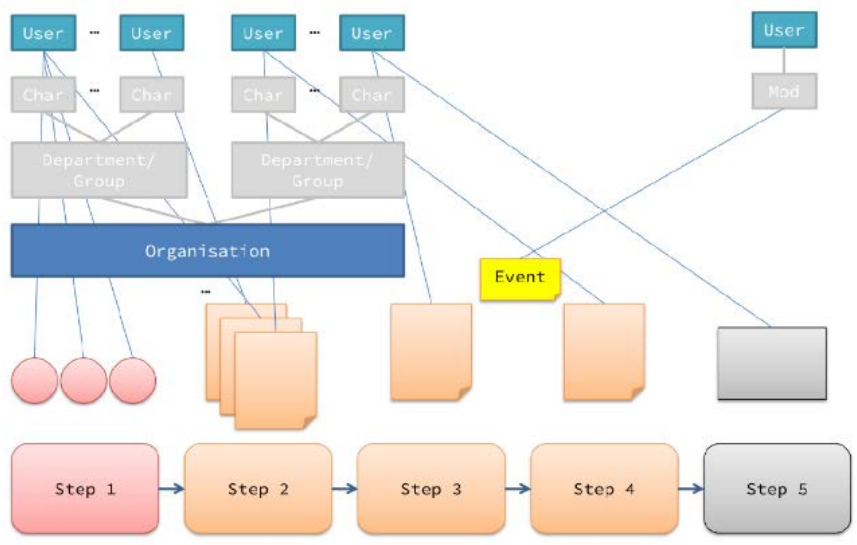

Figure 4. General setting of the Beware game play

The gaming scenario is process based and event triggered as illustrated in Figure 3. The game enables students to identify how different types of risks impact differently on the success of a cooperation, depending on the type of cooperation, previous performance and how the impact of risks increases and affects the partners' success over time, if no actions are taken to reduce and control the risks. To succeed, the students have to apply risk assessment and risk management methods and thus increase their awareness of risks in production networks as well as the complexity of decision making in dynamic environments.

Beware is process driven. A business process always refers to a company. Business processes can be inter-related, meaning that one company cannot continue with the next step in their business process until the other company has completed a specific step in their business process. Also the simulation engine only allows a current process step to be modified to ensure sequential processing of business process steps.

The game is implemented using the BMOG gaming engine $[24,30]$. The engine reads and executes game models providing an advanced user interface for the players. The game has been used since 2007, and has been regularly updated [26, 30]. Analysing the learning outcomes over the years show satisfactory results; the evaluation of the learning outcome on risk awareness and management indicate that the students were able to identify risks, apply risk assessment and management methods, as well as reporting that the game helped them to apply their theoretical knowledge and develop strategies. It also shows that the longer they play, the better they get at identifying and assessing the different types of risks at an early stage.[31]

The participants mentioned two main challenges (related to the game). Firstly, they lost the overview and did not manage to deal with the user interface and what was happening. Secondly, they found it difficult to identify hidden risks as well as sometime to understand how decisions in the production influence the product quality.

The results also revealed that for students without or with limited knowledge of risk management, it is important to make their task more visible in the first game level. In recent years, it was observed that student engagement with the SG lessened due to its dated UI and the graphical (old fashioned) design. Thus, it has been decided to modify the game and to give it a new interface.

The game is process driven and based on simplified processes from real companies. At the time the game was designed, none of these company processes included the usage of sensor data. Today, however, many production systems would provide data allowing early warning for risks and failures. This process data can be used in the game when played as a single, holistic system.

\section{Redesign}

The game redesign combines a physical replication in the LL and a digital workspace. The LL set up recreates the environment a production company, including shops floors and assembly line.

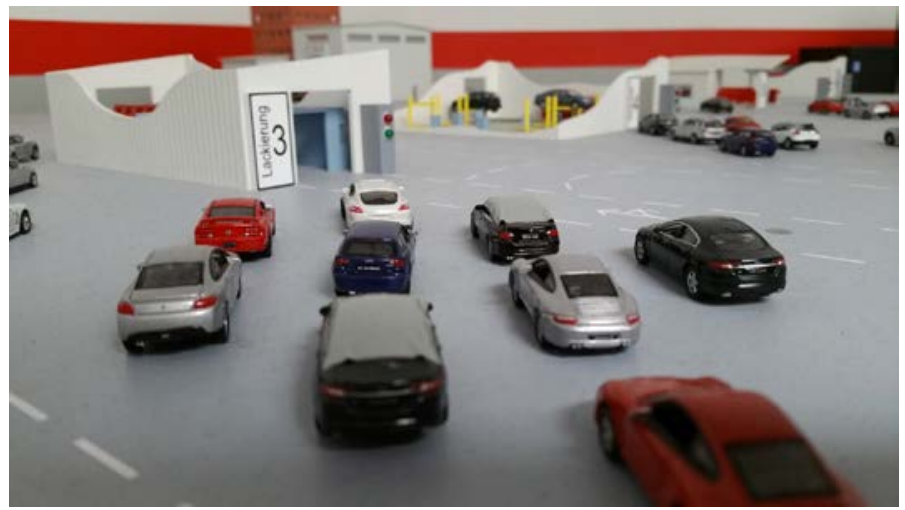

Figure 5. Simulation model of the finishing site of a car production 
Sensors for CPS and IoT are incorporated to communicate and interact with the game.

Figure 5 shows an analogue representation of Beware. In this physical rendition or diorama, sensors are installed (in the cars, in the lanes and in the work station (like in workstation 3 in the picture) to capture the time associated to a specific process of the product (a car in this case), the process quality (time in process, queuing time etc., sensor data on temperature and humidity etc. (in the CKD production the humidity and temperature influences the corrosion and the finishing of the parts) Such data is important in calculating the risk related to product quality as well as related logistic services, i.e. delivery time, supplier reliability, and other specific services.

In Figure 6, node n8 indicates a player starts to set up the production and the assembly lines. Data obtained from the CPS located in the diorama updates the game world as well as the database representing the warehouse (e.g. on stocking information). The streamed data is compared with the plan data in order to provide information on delays, quality etc. and ordering. Furthermore, for product development, quality both of the process as well as of the product component is of utmost importance. With the new hybrid environment, the collected sensor data can be used in different ways both to monitor the process as well as to give immediate feedback if the data are out of the range. This is used in the game play both for supporting the risk assessment, as well as for letting the student experience how the same data influences the different production steps in various ways.

Other aspects of the game are to reduce collaboration risks (P2, P8, P9). It is intended that IoT concepts when combined with CPS can be used to improve data and information communication and interactions. At present IoT and CPS data are asynchronously captured. We are currently investigating methods to capture the interaction among the players in the lab environment such that it can be seamlessly integrated in the game play. Other interaction modalities such as voice or registering the interactions among users in the game environment and in the LL environment concurrently are being considered. As the game is used for teaching students, ethical issues in collecting personalised data, particularly when that data is to be used it in game play, it is an issue that still needs to be resolved.

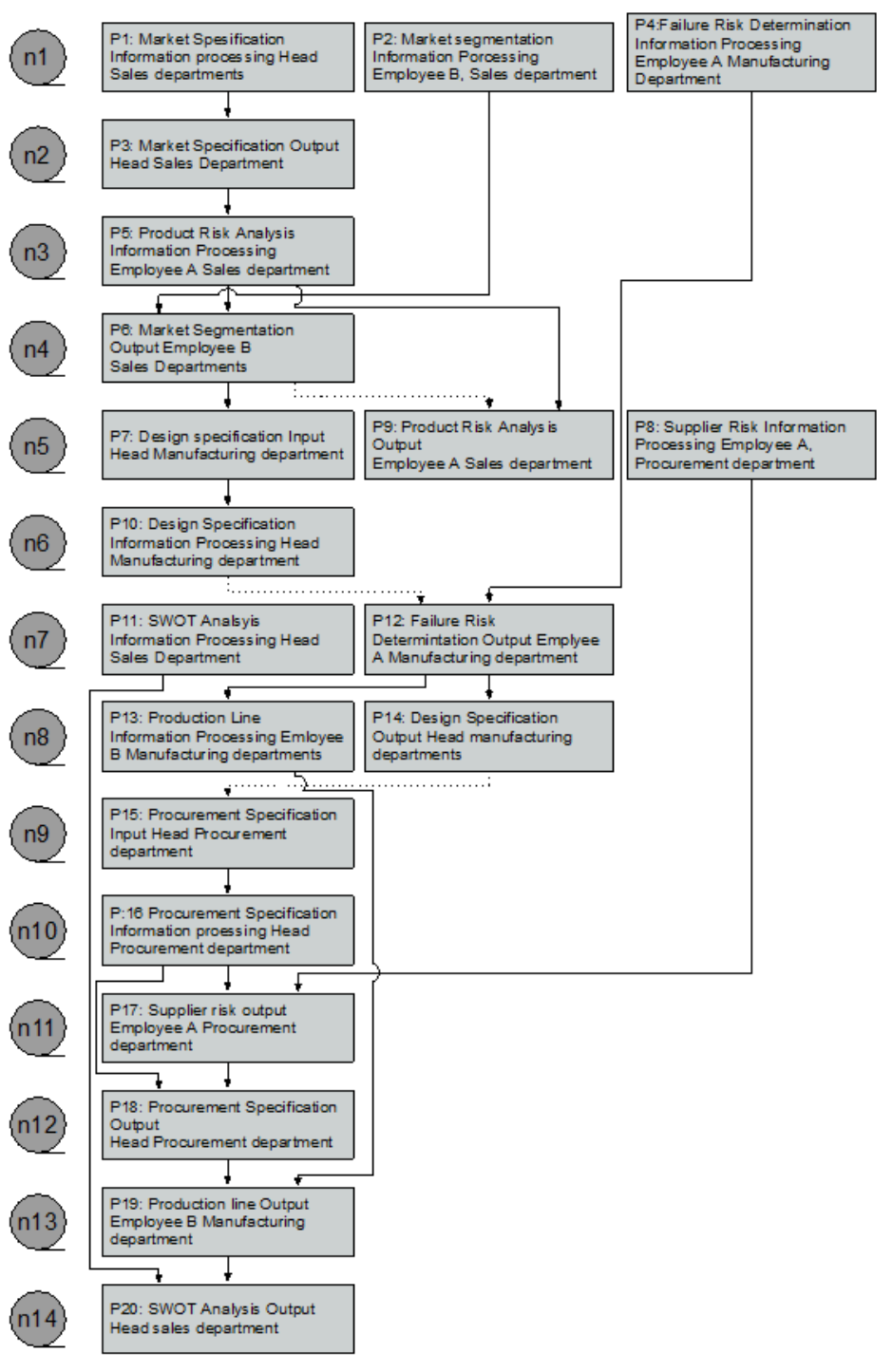

\section{Figure 6. Process overview first level Beware}

\section{CONCLUSION}

This paper has first reported on how a hybrid (real-virtual) environment can contribute to the ideation and creation of IoT based services in the logistics. The second part of the paper deals with how this experience can be transferred and used in making existing digital educational games more engaging and pervasive. The article describe the redesign of a game used for teaching engineers risk management in distributed production. The game is still in the redesign process, so only preliminary have been carried out. These tests show that the use of sensor data coming from a real environment, where the students are involved and can change increases their understanding of how risks occurs both in the product as well as in the production process, and also how the same data can be used to monitor and reduce risks. 


\section{ACKNOWLEDGMENTS}

The work presented herein is partially funded under the European H2020 Programme BEACONING project, Grant Agreement nr. 687676.

\section{REFERENCES}

[1] Starkey, K., and Tempest, S. (2005), "The future of the business school: Knowledge challenges and opportunities”, Human Relations, Vol. 58, No. 1, pp. 61-82

[2] Prensky, M. (2003) Digital game-based learning, ACM Computers in Entertainment, Vol. 1, No. 1, pp. 21-21.

[3] GEE, J. P. (2003). What video games have to teach us about learning and literacy. New York: Palgrave Macmillan.

[4] Ebner, M. and Holzinger, A. (2007). Successful implementation of user-centered game based learning in higher education: An example from civil engineering. Computers \& Education, 49 (3), 873-890.

[5] Bellotti F., Berta R. and De Gloria, A. (2010) Designing Effective Serious Games: Opportunities and Challenges for Research, Special Issue: Creative Learning with Serious Games, Int.l J. of Emerging Technologies in Learning (IJET), Vol. 5, pp. 22-35

[6] Greitzer, F. L., Kuchar, O. A. and Huston, K. (2007) Cognitive Science Implications for Enhancing Training Effectiveness in a Serious Gaming Context, ACM J. Educational Resources in Computing, Vol. 7(3) Art $2 \quad$ ), 10 pages. $\mathrm{DOI}=10.1145 / 1281320.1281322$

[7] Baalsrud Hauge, J., Kalverkamp, M., Bellotti, F., Berta, R., De Gloria, A., Barabino, G., "Requirements on learning analytics for facilitated and non facilitated games," Global Engineering Education Conference (EDUCON), 2014 IEEE , vol., no., pp.1126,1132, 3-5 April 2014 doi: 10.1109/EDUCON.2014.6826251

[8] Kerns, S. E., Miller, R. K. Kerns, D. V. (2005) Designing from a blank slate: the development of the initial Olin college curriculum, in Educating the Engineer of 2020: Adapting Engineering Education to the new century, http://www.nap.edu/catalog/11338.html, accessed 20.12.2012

[9] Cheville, A. and Bunting, C. (2011) Engineering Students for 21st Century: Student Development Through the Curriculum, J. of Adv. in Engineering Education $\operatorname{VOl}(3(4)$ pp1-37, http://advances.asee.org/wpcontent/uploads/vol02/issue04/papers/aee-vol02-issue04-p10.pdf accessed 30.4.2014

[10] O’Sullivan, B. Rolstadås, A. and Filos, E. (2011) Global education in manufacturing strategy, Intellectual Manufacturing, Vol. 22, pp. 663-674.

[11] Chryssolouris, G. and Mavrikios, D. (2007) Education for Next Generation Manufacturing, Paper presented at IMS Vision Forum 2006, available at ftp://ftp.cordis.europa.eu/.../gc_to_imsvisionforum2006-paper.pdf

[12] Baalsrud Hauge, J., Hoeborn, G., and Bredtmann, J. (2012) Challenges of Serious Games for Improving Students' Management Skills on Decision Making, Handbook of Research on Serious Games as Educational, Business and Research Tools: Development and Design, M. Cruz-Cunha and Joao Varajao (Eds), IGI Global, pp.947-964

[13] Narayanasamy, V., Wong, K. W., Fung, C. C. and Rai, S. (2006) "Distinguishing Games and Simulation Games from Simulators", Computers in Entertainment, Vol. 4(2), pp. 1-18.
[14] Kriz, W. (2001) How to facilitate the debrief of simulations/games for effective learning, in: Psychologische Bericht

[15] CERP IoT: Internet of Things Strategic Research Roadmap", 2009; http://www.grifs-project.eu/data/File/CERPIoT\%20SRA_IoT_v11.pdf, accessed 14.2.2013

[16] L4LIFE (2011): Roadmap on ICT for sustainable Freight Transport and Logistics; Version 1.0, Logistics for LIFE Coordination Action (http://www.intelligentcargo.eu/sites/intelligentcargo.eu/files/roadma p_v10.pdf); accessed 05.02.2013; 22:00h)

[17] Moseng, T.K and Natvig, M.: Smarter Tunnels - Integration with Traffic Management, Tunnels and ITS Symposium, Bergen, June 2011

[18] Følstad,A.(2008): TOWARDS A LIVING LAB FOR THE DEVELOPMENT OF ONLINE COMMUNITY SERVICES, The Electronic Journal for Virtual Organizations and Networks; Volume 10, pp. 47-58.

[19] Schumacher, J., \& Niitamo, V.-P. (2008). European Living LAbs - A new approach for human centric regional innovation. Berlin: Wissenschaftlicher Verlag Berlin.

[20] Schumacher, J., Gschweidl, M. Rieder, M.: EURIDICE, Platform Architecture in Logistics for „The Internet of Things“. In: In: Kreowski, H-J, Scholz-Reiter, B., Thoben, K-D: Dynamics in Logistics, Proceedings, LDIC 2009, Springer, 2011, pp.235-244

[21] Kalverkamp, M.; Baalsrud Hauge, J.; Thoben, K.-D. (2013) Logistics IoT services development with a sensor toolkit in an experiential training environment In: Cunningham, S. W.; Salimi, N.; Ortt, R.; Rezaei, J.; Katzy, B. R. (Eds.): Proceedings of the IEEE International Technology Management Conference and 19th. International Conference on Concurrent Enterprising (IEEE-ITMC\&ICE 2013), The Hague, The Netherlands

[22] Baalsrud Hauge, J.; Kalverkamp, M. (2013) Creating an IoT-GameToken for a Serious Game in Logistics In: Proceedings of the International Simulation and Gaming Association and the 17th IFIP WG 5.7, Workshop on Experimental Interactive Learning in Industrial Management (ISAGA 2013); Stockholm, Sweden

[23] Hesmer, A., Hribernik, K. A. Baalsrud-Hauge, Thoben, K.-D.: Supporting the Sytematization of Early-Stage-Innovation by Means of Collaborative Working Environments; in: IFIP International Federation for Information Processing; Volume 250/2007; Springer, Boston, 2007, pp 135-144

[24] Elliot consortium (2011): D3.3 ELLIOT Platform Serious Gaming approach to support usability of IOT oriented user co-creation

[25] Baalsrud Hauge, J.; Duin, H. (2012). Challenges and Opportunities of Using Games for Supporting Creativity. In: Urban, B.; Müsebeck, P. (Eds.): eLearning Baltics, Proceedings of the 5th International eLearning Baltics Conference (eLBa 2012), Rostock, 20-22 June 2012

[26] Baalsrud Hauge, J. (2014) The use of gamebased learning methods for teaching supply chain management subjects. In: Journal of Advanced Distributed Learning Technology (JADLeT 2014), Volume 2, (5), S. 5-15, USA

[27] Kolb, D.: Experiential Learning: Experience as the Source of Learning and Development. Prentice-Hall, New Jersey (1984)

[28] Hesmer, A., Hribernik, K. A. Baalsrud-Hauge, Thoben, K.-D.: Supporting the Systematization of Early-Stage-Innovation by Means of Collaborative Working Environments; in: IFIP International Federation for Information Processing; Volume 250/2007; Springer, Boston, 2007, pp. 135-144

[29] Corti, K.: Games-based Learning; a serious business application. PIXELearning Limited, 2006

[30] Baalsrud Hauge, J. Duin,H; Thoben; K-D.,, (2008a).: Reducing Network Risks in Supply Networks by Implementing Games for Mediating Skills on Risk Management. In: Cunningham, P. and Cunningham, M: Collaboration and the Knowledge Economy: Issues, Applications, Case Studies. IOS Press. Amsterdam, Berlin, Oxford, Tokyo, Washington DC 2008. S. 707-714 
[31] Baalsrud Hauge, J.; (2015) Mediating skills on risk management for improving the resilience of Supply Networks by developing and using a serious game, Universität Bremen (PhD thesis)

[32] Koestler, A.(1964): The act of creation. London Hutchinson \& Co. (1964)

[33] Dalcher, D.(2006) Consilience for universal design: the emergence of a third culture. Universal Access in the Information Society, 5 (3) 253-268

[34] Wendrich, R. (2013): The Creative Act is done on the Hybrid Machine. Proc. of 19th Int. Conf. on Eng. Dgn. (ICED2013) (2013) 